\title{
Gas comprehensive prevention and control technology and practice in outburst mine
}

\author{
GAO Hong ${ }^{1}$ \\ ${ }^{1}$ School of Energy and Safety, Anhui University of Science and Technology, Huainan 232001; China; State Key Laboratory of Mining \\ Response and Disaster Prevention and Control in Deep Coal Mines, Huainan 232001; China Coal Technology and Engineering Group \\ Shenyang Research Institute, Fushun,113122, China; State Key Laboratory of Coal Mine Safety Technology, Fushun,113122, China
}

\begin{abstract}
In view of the present situation of gas occurrence in Xiaoxi coal industry, combined with the problems of high gas pressure, high content and complex geological structure in the gas control, the comprehensive gas prevention and control technology to meet the mining connection is proposed.It mainly includes the pre drainage measures of underground kilometer drill hole, through layer drilling and bedding drilling, comprehensive gas prevention technology of surface well pre drainage of coal seam gas and underground cross layer drilling area outburst prevention. The practice shows that after the implementation of comprehensive gas control measures, the residual gas content and gas pressure of coal seam are greatly reduced, and the gas control effect is remarkable. Through the comprehensive gas control technology of outburst mine, the gas control level of Xiaoxi coal industry has been significantly improved, and the number of times of gas overrun has decreased year by year.
\end{abstract}

\section{Introduction}

At the same time, it is affected by the geological factors, such as the coal seam thickness and gas outburst, which is affected by the coal mine depth and gas outburst.Therefore, it is necessary to strengthen gas control to ensure the production safety and sustainable development of coal mines.

Through the analysis of coal seam occurrence conditions and gas control status in Xiaoxi coal mine, based on the summary of existing gas control achievements and main problems, the goal of comprehensive gas control is formulated. Combined with the actual situation of the mine, the comprehensive gas control technology suitable for Xiaoxi coal industry is put forward. At the same time, a series of suggestions on scientific and technological progress and safeguard measures are put forward.

\section{Mine overview}

The No.3 coal seam of Shanxi Yangcheng Yangtai group Xiaoxi Coal Industry Co., Ltd. is characterized by maximum gas content of $15.61 \mathrm{~m}^{3}$; residual gas content of $2.84 \mathrm{~m}^{3}$; initial gas emission velocity of $27.8 \mathrm{mmHg}$; coal firmness coefficient $\mathrm{f}=0.51$; maximum gas pressure of coal seam is $1.66 \mathrm{mpa}$; adsorption constant a is $34.99 \mathrm{~m}^{3} / \mathrm{t}$, $\mathrm{B}$ is $1.63 \mathrm{~m}^{3} / \mathrm{t}$; porosity is $6.3 \%$; permeability coefficient of coal seam is $3.4779 \mathrm{~m}^{2} / \mathrm{Mpa}^{2} \cdot \mathrm{d}$; the attenuation coefficient of gas flow in $100 \mathrm{~m}$ borehole is $0.035 \mathrm{~d}^{-1}$.

The coal mine of Xiaoxi Coal Industry Co., Ltd. of
Yangtai group in Yangcheng, Shanxi is a coal and gas outburst mine. The absolute gas emission is $46.6 \mathrm{~m}^{3} / \mathrm{min}$, and the corresponding coal seam mining depth is $+620 \mathrm{~m}$. With the increase of buried depth, the difficulty of gas control becomes more and more difficult. According to the current average mining depth of Qincheng Coal Mine and Wujia coal mine in the north of No.1 mining area, the mining depth of the mine will gradually increase, it brings great pressure to the mine gas control. Therefore, it is necessary to strengthen the gas control to ensure the production safety and sustainable development of the coal mine.

\section{Technical scheme for comprehensive gas prevention and control}

Through the analysis of the existing gas outburst prevention measures, the existing gas outburst prevention and control measures should be taken to eliminate the gas outburst.The gas control strategy of "local outburst prevention measures as supplement" should be transferred and the gas control mode of "pre drainage of coal seam gas with the combination of underground kilometer drilling rig drilling, cross layer drilling and bedding drilling", "surface well pre drainage of coal seam gas" and "underground cross layer drilling area outburst prevention" are established to realize the safe and efficient production of the mine and fundamentally reduce the threat of coal mine gas disaster ${ }^{[1-2]}$.

*Corresponding author: E-mail: g.h.f.w@163.com. Company email: webmaster@aust.edu.cn. 


\section{Practice of comprehensive gas control technology}

\section{1 pre pumping measures of combination of borehole drilling, cross layer drilling and bedding drilling}

(1) First regional outburst prevention measures in East Wing of panel 1

The 3108 working face of No.1 panel of Xiaoxi Coal Industry Co., Ltd. is the first mining face in the east wing of panel 1 , and the gateway of the working face is being excavated. When mining the east wing of panel 1 , due to the four working faces of 3108, 3106, 3104 and 3102, during the construction of the main roadway in panel 1 , directional long boreholes have been constructed in the direction of the East Wing working face with the length of $420 \mathrm{~m}$ and the spacing of $5 \mathrm{~m}$, covering the whole area.As shown in Figure 1.

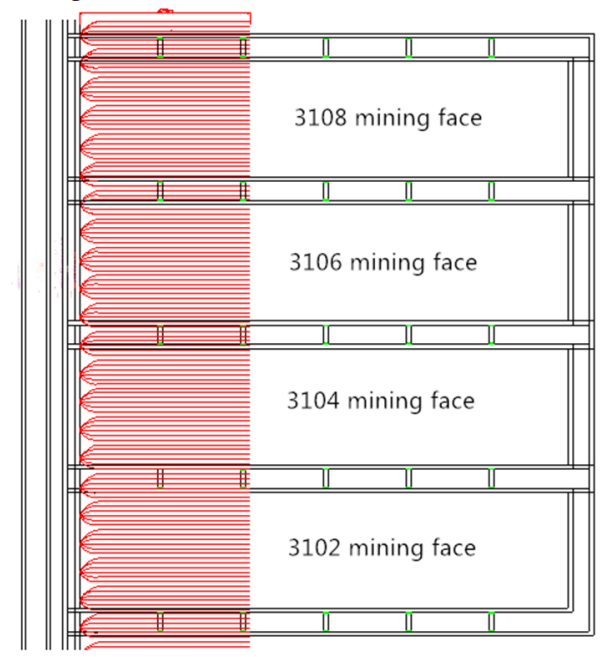

Fig1. First regional outburst prevention measures in East Wing of panel 1

(2) Regional outburst prevention measures for auxiliary return air roadway

A group of cross layer boreholes are constructed in the return air roadway of panel 1 to extract the auxiliary return air roadway. A group of cross layer boreholes are constructed every 6 meters. The fan-shaped arrangement is adopted for the boreholes. Seven boreholes are constructed in each group of cross-layer boreholes, and the final hole spacing is not greater than $6 \mathrm{~m}$. At present, 1071 $\mathrm{m}$ has been safely driven, and only $129 \mathrm{~m}$ of auxiliary return air roadway in panel 1 is excavated to the boundary of the mine field. In other words, a group of through layer boreholes are constructed in the return air roadway of panel 1 for extraction. A group of cross layer boreholes are constructed $6 \mathrm{~m}$, and 7 boreholes are constructed in each group of through layer boreholes, and the final hole spacing is not greater than $6 \mathrm{~m}$, as shown in Figure $2^{[3]}$.

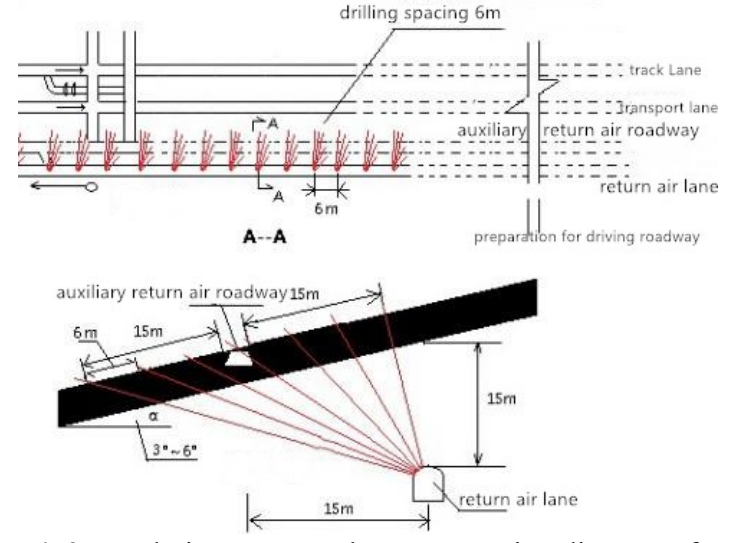

Fig2. Pre drainage gas outburst prevention diagram of auxiliary return air roadway in panel 1

(2) outburst elimination in working face area

No.3 coal seam of Xiaoxi Coal Industry Co., Ltd. of Shanxi Yangtai group belongs to the coal seam that can be extracted. According to the layout design of the mine working face, taking 3108 working face in the east wing of the first panel as an example, the directional long drilling hole is mainly used for outburst elimination in the heading face, that is, after the heading working face of 3108 working face is 400 meters, the directional drilling rig is constructed head-on.In the drilling site, the directional long drilling hole with $\oint 96 \mathrm{~mm}$ hole diameter is constructed, the length is $350 \mathrm{~m}$, the design branch hole spacing is $6 \mathrm{~m}$, and the control distance outside the roadway contour is $15 \mathrm{~m}$; the boreholes are evenly arranged to ensure that there is no goaf.If the distance between the next hole and the next hole reaches the standard, it is necessary to verify the effect of the above measures.

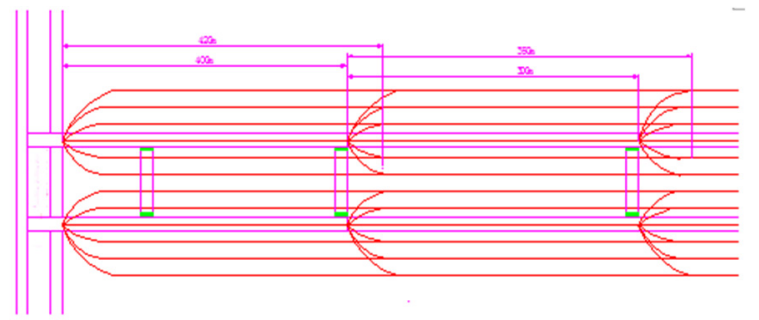

Fig3. Schematic diagram of gateway pre pumping of working face

After the heading of 3108 working face is driven, the 3108 gateway is used to construct horizontal pre drawing long boreholes to the next working face. In order to avoid the extraction blank area, the directional drilling machine is used for the pre extraction drilling. The length is $15 \mathrm{~m}$ outside the contour line of the next working face and passes through the whole working face. The distance between the drilling fields in the heading is $80 \mathrm{~m}$. The deepest drilling hole is $300 \mathrm{~m}$ and the shortest drilling hole is $150 \mathrm{~m}$. The horizontal projection length of the boreholes controlling the next working face gateway is about $260 \mathrm{~m}$ (the length of the working face is about $210 \mathrm{~m}$, the width of the gateway is about $5 \mathrm{~m} \times 2$, and the width of the coal pillar is $25 \mathrm{~m}$ ). The control range of each drilling site is $80 \mathrm{~m} * 260 \mathrm{~m}$, and the spacing of branch holes is $6 \mathrm{~m}$, which is evenly arranged. 
In the area that cannot be covered by directional drilling rig, the additional drilling hole diameter is $\oint$ $94 \mathrm{~mm}$, and the drilling spacing is $6 \mathrm{~m}$, so as to ensure that there is no blank area.As the $420 \mathrm{~m}$ long regional outburst prevention boreholes constructed by return air roadway in the east wing of panel 1 have covered 4 working faces of $3108,3106,3104$ and 3102, the layout of outburst prevention measures in the gateway area of the other three working faces except 3108 working face is shown in Figure 4.

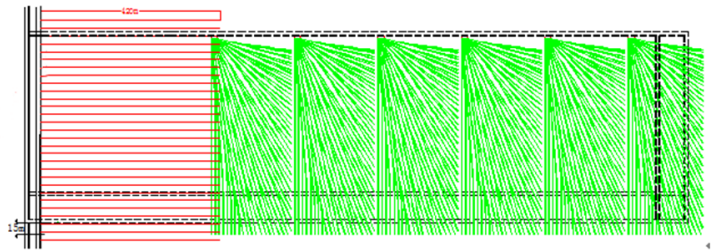

Fig4. Outburst prevention diagram of other working faces in panel 1

For the coal seam with stable gangue layer and natural stratification area, it is necessary to arrange a row of regional outburst prevention drilling holes in each coal seam whose thickness is greater than $0.3 \mathrm{~m}$, and the borehole layout parameters are the same as the above parameters.

Due to the stable occurrence of coal seam, high coal firmness coefficient and good permeability, through layer drilling is mainly used to eliminate outburst in regional coal body, and then pre pumping along the seam is carried out to eliminate outburst.At the same time, a floor rock roadway is arranged in the first mining face. After the floor roadway forms the ventilation system, and the outburst is eliminated by drilling through the layer, the gateway is pre pumped ${ }^{[4]}$.The long-term engineering practice shows that the scheme is technically feasible.

The specific implementation plan is as follows: the drilling is arranged in the way of long boreholes, covering the whole gateway of the next working face, and it exceeds the gateway by $15 \mathrm{~m}$. The hole diameter of the hole is $\oint$ $94 \mathrm{~mm}$, the distance between the holes is about $1.5 \mathrm{~m}$ from the roadway floor, and the distance between the holes is $6 \mathrm{~m}$. The strike length of No.3 coal face is $190 \mathrm{~m}$, the width of coal pillar is $25 \mathrm{~m}$, the gateway is $4.5 \mathrm{~m}$, and the length of the final borehole is $250 \mathrm{~m}$.By analogy, all stoping faces in the West Wing of panel 1 adopt progressive outburst elimination.

When the working face gateway drainage reaches the standard, after the excavation is completed, the directional long drilling hole is used to construct the next working face gateway coal seam, and the regional outburst prevention measures are taken.Long boreholes are arranged in the coal seam for pre pumping, and the long pre pumping boreholes must cover all the gateways of the next mining face.In the areas that cannot be covered by directional drilling rig, ordinary drilling rig shall be used to supplement drilling holes, so as to ensure that there is no blank area ${ }^{[5]}$. By analogy, the progressive gas drainage method is used in other working faces in the east wing of the first panel to eliminate outburst.

\section{2 surface well pre drainage of coal seam gas}

The distance of pre drainage coal seam gas from surface wells is generally about $200 \sim 350$ m. According to the experience of gas drainage from surface boreholes in Jincheng area, the gas content in coal seam can only be reduced by about $1 \mathrm{~m}^{3} / \mathrm{t}$ for every $300 \mathrm{~m} \times 300 \mathrm{~m}$ surface boreholes. The maximum gas content in the mining area of Xiaoxi coal industry is as high as $19.28 \mathrm{~m}^{3} / \mathrm{t}$. If only the surface borehole drainage method is adopted, it is preliminarily estimated that the net gas quantity of $1 \mathrm{~m}^{3} / \mathrm{t}$ of pre drainage coal seam per year can reach the standard after 11 years of pre drainage.

There are 140 surface pumping wells designed in Xiaoxi coal mine, including 60 vertical wells and 28 directional wells (each directional well has 3 branch wells). The pumping wells are arranged according to the density of $12.94 / \mathrm{km}^{2}$. The average pumping capacity of each well is $2000 \mathrm{~m}^{3} / \mathrm{d}$, and the total design pumping gas volume is $200000 \mathrm{~m}^{3} / \mathrm{d}$.

The pre drainage of gas surface wells in Xiaoxi coal industry has reliable resource guarantee, large gas production potential, and can effectively reduce gas content; the technology and technology adopted are relatively mature, and have strong adaptability to Xiaoxi coal industry; the utilization market is good and the economy is strong.Surface well pumping is mainly used to assist regional outburst elimination.

\section{3 outburst prevention in cross layer drilling area}

In the process of mining the first mining face, the air intake chute mainly relies on the pre pumping of through layer drilling to eliminate outburst.The bottom drainage roadway is arranged 15 meters below the middle bottom plate of 3103 air inlet channel and 3105 return air gateway. In the bottom suction roadway, outburst is eliminated for belt air inlet chute and 3105 rail return air gateway of 3103 working face. A group of cross layer boreholes are constructed every 6 meters. The fan-shaped arrangement is adopted. 12 boreholes are constructed in each group, and the final hole spacing is not more than $6 \mathrm{~m}$. The construction is gradually carried out with the advance of bottom extraction roadway, The drilling angle is $29^{\circ}$ to $152^{\circ}$ and the length is about $28 \mathrm{~m} \sim 45 \mathrm{~m}$, which is subject to the full thickness of the coal seam and then constructed for 3M.In the process of drilling, the hole spacing shall be $6 \mathrm{~m}$ and the hole sealing shall not leak.Taking 3103 working face as an example, the regional outburst elimination scheme is shown in Fig. 5. 


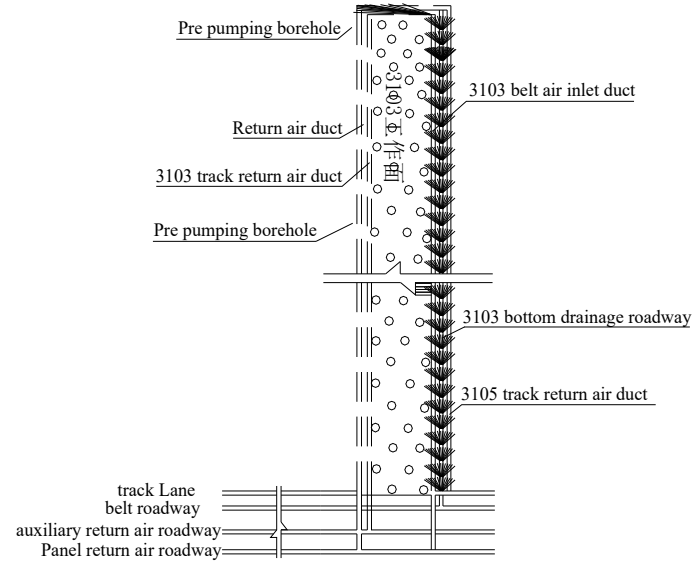

(a) Layout plan of outburst prevention drilling in 3103 working face

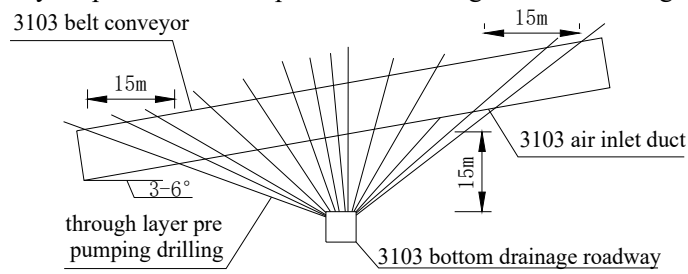

(b) Section layout of outburst prevention boreholes in 3103 working face

Fig5. Regional outburst prevention scheme 3 of Xiaoxi coal industry 3103 working face

Surface well pre drainage of coal seam is widely used in Huainan and Jincheng, and underground borehole pre drainage of coal seam gas is also widely used in Huainan.It not only ensures the high efficiency of the drilling and the surface drainage, but also ensures the pumping efficiency.

\section{Evaluation of gas control effect}

According to the regional outburst prevention measures of Xiaoxi coal industry, the indexes of drilling cuttings desorption, gas pressure and residual gas content are selected as the test indexes. The residual gas content is reduced to less than $8 \mathrm{~m}^{3} / \mathrm{min}$ and the gas pressure is reduced to less than $0.74 \mathrm{MPa}$.

Through the comprehensive control of mine gas, the level of gas control in Xiaoxi coal industry has been significantly improved, the number of times of gas overrun has decreased year by year, the casualties caused by gas have been eliminated, and the mine safety production has been effectively promoted.To carry out gas comprehensive control project in outburst mine has double effects on mine safety production and environmental protection, and can achieve double harvest of economic and social benefits.

\section{Conclusion}

(1) Through the implementation of pre pumping measures in 1308 mining face of the east wing of the first panel, the combination of underground kilometer drilling, cross layer drilling and bedding drilling was carried out, and the ordinary drilling machine was used to supplement the construction drilling holes in the area that the directional drilling machine could not cover, so as to ensure the full coverage of the extraction area.The measures of pre drainage of coal seam gas by surface wells are designed, and the pre drainage of coal seam gas by surface wells is finally taken as the auxiliary regional outburst prevention measures.Through adopting the outburst elimination measures in the area of pre drainage of coal seam gas by cross layer drilling in the air intake gateway of the first mining face, the driving of the gateway is safely protected.

(2) Field practice shows that after the implementation of comprehensive gas control measures, the residual gas content of coal seam is reduced to less than $8 \mathrm{~m}^{3} / \mathrm{min}$, and the gas pressure is reduced to less than $0.74 \mathrm{Mpa}$, and the gas control effect is remarkable.

\section{Corresponding author:}

Gao Hong (1985-), male, from Gongyi, Henan Province, assistant researcher, engaged in the research on prevention and control of coal mine gas disaster. E-mail: g.h.f.w@163.com. Company email : webmaster@aust.edu.cn.

\section{Acknowledgments}

The author would like to thank all editors and anonymous reviewers for their comments and suggestions. This research was financially supported by the Special Youth Project of Science and Technology Innovation and Entrepreneurship Funding from China Coal Technology and Engineering Group Co., Ltd. (Research and development of control software for gas drainage and drilling: 2018-2-QN015).

\section{Reference}

1. Zhao Weimin, Li Xiangge, Feng enhu, Wei Yanyong. Practice of comprehensive gas control technology in Baoan coal outburst mine $[\mathrm{J}]$. Coal mine safety, 2012,43 (10): 52-55

2. Gas outburst prevention and control technology of yangyangao coal mine [40.40, 2012]

3. Li Hong, Liu Mingju, Gao Hong. Gas drainage technology and practice of large mining height working face in high outburst mine $[\mathrm{J}]$. China safety production science and technology, 2019, 15 (06): 99104

4. Gao Hong, Yang Hongwei, Qian Zhiliang. Study on Optimization Technology of high level borehole in working face at the end of mining period $[\mathrm{J}]$. Coal engineering, 2019,51 (06): 108-111

5. Zhou Ting Yang, Li Qifa. Research on gas prevention and control technology of Stratified Mining in high gassy thick coal seam [J]. Coal engineering, 2017, 49 (S2): $53-57+61$ 